\title{
O paradoxo da mudança
}

Nuno Jacinto ${ }^{1}$

$\mathrm{N}$ os últimos meses, todos temos vivido tempos conturbados. Esta tem sido uma época plena de desafios inesperados, marcada por um aparente paradoxo, entre a necessidade de mudança e a continuidade do que nos define enquanto seres humanos e, no nosso caso, médicos de família. Mas serão estas realidades inconciliáveis?

A pandemia obrigou-nos a mudar hábitos, comportamentos e atitudes. Tivemos de nos adaptar a este novo normal, adaptação essa que ainda não está concluída e que, frequentemente, ocorre de forma difícil e atribulada. Mas a mudança é muitas vezes necessária, desejável e benéfica. Estamos a passar por esse processo na Associação Portuguesa de Medicina Geral e Familiar (APMGF), uma associação que sempre se soube renovar e responder às exigências dos tempos e contextos em que se insere.

Por outro lado, a mudança apenas faz sentido quando tem um objetivo claro de melhoria. Mudar só por mudar não tem interesse e pode até ser prejudicial. Em algumas ocasiões importa apostar numa evolução na continuidade, aprimorando virtudes e corrigindo aspetos menos positivos. É, por isso, com enorme satisfação que assistimos à entrada em funções desta nova equipa editorial da Revista Portuguesa de Medicina Geral e Familiar (RPMGF), alicerçada no que de bom se fez no passado, dando seguimento ao trabalho de qualidade que tem sido desenvolvido, mas com os olhos postos no futuro, movidos pelo desejo de fazer ainda mais e melhor.

A RPMGF é uma referência da medicina geral e familiar (MGF) portuguesa e é um enorme motivo de orgulho para a APMGF. A nossa revista eleva a nossa especialidade, dá palco ao conhecimento científico e divulga a investigação que tem lugar no nosso país. Claro que temos de ser ambiciosos e ter a consciência que ainda há um longo caminho a percorrer. Mas a solidez dos passos dados pela RPMGF ao longo dos anos faz-

1. Presidente da Associação Portuguesa de Medicina Geral e Familiar. Lisboa, Portugal. Médico de Família, USF Salus, ACeS Alentejo Central. Évora, Portugal.

Presidente do Conselho Clínico e de Saúde do ACeS Alentejo Central. Évora, Portugal. -nos encarar com tranquilidade todos os desafios que se perfilam no horizonte.

Todos desejamos sair rapidamente desta pandemia que nos assola. $\mathrm{O}$ mundo não voltará a ser o mesmo e muito irá mudar. Muito já mudou. Durante estes meses, a RPMGF continuou o seu percurso, manteve o ritmo, trazendo até nós uma centelha da normalidade que víamos (e ainda vemos) distante e mostrando que o conhecimento científico que sustenta a nossa especialidade não conhece barreiras e consegue ultrapassar todos os obstáculos. Este papel desempenhado pela RPMGF é absolutamente essencial para o crescimento e reforço do prestígio da MGF em Portugal e sê-lo-á ainda mais a curto e médio prazo, num mundo marcado pela tal mudança. A comunicação continuará a evoluir e a modificar-se, os prazos serão cada vez mais exigentes e a velocidade a que o conhecimento avança e se modifica não se compadece com procedimentos rígidos e anacrónicos. Estou certo de que a renovada equipa editorial da RPMGF, que merece a maior confiança e agradecimento por aceitar uma tão nobre mas igualmente complexa tarefa, saberá em cada momento encontrar as melhores soluções para todas estas exigências.

Também a APMGF continuará o seu caminho, honrando o passado e contribuindo sempre com ideias e soluções inovadoras que dignifiquem e desenvolvam a MGF, de modo a responder às crescentes necessidades dos utentes de quem cuidamos.

Tal como até aqui, estaremos sempre disponíveis para combater a pandemia e já demos múltiplas provas do nosso esforço e dedicação. Estivemos sempre ao lado dos nossos doentes e não é agora que os deixaremos. Contudo, é crucial que seja aliviada a carga burocrática que nos tem sido imposta e que sejamos dispensados de tarefas que podem ser realizadas por outros profissionais, libertando-nos para que possamos realizar as atividades que apenas podem e devem ser feitas por nós.

Não podemos continuar a olhar para os cuidados de saúde primários (CSP) e para os médicos de família como um saco sem fundo, nem permitiremos que 
olhem para nós com base numa lógica meramente aritmética, como simples células numa qualquer folha de cálculo. Somos muito mais do que isso, pelo que não deixaremos de insistir em algo que para nós, enquanto APMGF, é fundamental: têm de nos ser dadas condições para prestarmos os cuidados que todos os nossos doentes merecem.

Esta grande crise constitui uma oportunidade de ouro para reformar o Serviço Nacional de Saúde, afirmando de forma clara a centralidade dos CSP e da MGF. A mu- dança de que tenho falado passa, também e sobretudo, por aqui. Mas voltando ao tal paradoxo que referi no início, há algo que permanecerá inalterado: continuaremos a acompanhar os nossos doentes em todas as fases da sua vida, em especial quando estão mais vulneráveis. Seremos sempre médicos de família por inteiro.

ENDEREÇO PARA CORRESPONDÊNCIA

E-mail: nunofjacinto@gmail.com 